\title{
Investigating the appropriate mode of expressing lysine requirement of fish through non-linear mixed model analysis and multilevel analysis
}

\author{
Katheline Hua \\ Faculty of Agriculture and Horticulture, Humboldt-Universität zu Berlin, Invalidenstraße 42, 10115 Berlin, Germany \\ (Submitted 6 January 2012 - Final revision received 22 May 2012 - Accepted 23 May 2012 - First published online 24 July 2012)
}

\begin{abstract}
Accurate estimates of lysine requirement are essential to fish feed formulation. However, controversy exists regarding the most appropriate mode to express lysine requirement. In the fish nutrition literature, essential amino acid (AA) requirement has been expressed as a percentage of diet, a percentage of dietary crude protein or a ratio to dietary digestible energy (DE). The controversy lies in the different assumptions regarding the effects of dietary protein and DE on lysine requirement. Non-linear mixed model analysis and multilevel analysis were carried out to investigate whether dietary protein or DE affected lysine requirement of fish. The non-linear mixed model analysis suggests that expressing lysine requirement as a percentage of dietary protein provides a better goodness of fit to the modelling dataset than expressing requirement as a fixed concentration of diet, which in turn is generally better than expressing requirement as a ratio to DE. Results from the multilevel analysis confirm that dietary protein content has a significant effect on lysine requirement, while DE does not. The findings of the present study could contribute to a better understanding of the underlying dietary factors that affect AA requirements of fish. The results of the present study could also be useful for developing nutritional guidelines and feed formulations for fish.
\end{abstract}

Key words: Requirements: Lysine: Protein: Energy: Fish

One of the fundamental aspects of animal nutrition and feeding is the accurate determination of the requirement of essential amino acids (EAA) ${ }^{(1)}$. Lysine is commonly the first limiting AA in fish feeds, especially when feeds are formulated with high levels of plant protein ingredients. This is because fish meals and animal protein ingredients are generally rich in lysine, whereas plant protein ingredients, especially cereal grain by-products, are poor in lysine content. As fish meals and animal protein ingredients are increasingly being substituted by plant protein ingredients in fish feeds, an accurate estimate of lysine requirement is not only critical to costeffective feed formulation but also important to minimise environmental and ecological impact of aquaculture activities through nutritional strategies.

A better application of lysine requirement estimates in practical feed formulation faces several issues. First, estimates of lysine requirement for fish reported in the literature are highly variable. Moreover, one of the most controversial topics is the different modes of expressing EAA requirements in the literature ${ }^{(2)}$. Underlying this controversy are different assumptions regarding the effect of dietary composition (crude protein (CP) and digestible energy (DE)) on EAA requirements. Bureau \& Encarnação $^{(3)}$ reviewed these different opinions: (1) EAA requirements can be expressed as a percentage of diet (\% diet), which implies that EAA requirements are independent of dietary nutrient composition. This is commonly used by most fish nutritionists but difficult to justify because nutrient requirements are expected to be influenced by digestible nutrient compositions ${ }^{(2)}$. (2) EAA requirements can be expressed as a percentage of dietary CP (\% protein), which assumes that EAA requirements are a function of dietary protein content. (3) EAA requirements are expressed in relation to $\mathrm{DE}$ as $\mathrm{g} / \mathrm{MJ} \mathrm{DE}$, which assumes that EAA requirements depend on dietary DE content. In their review, Bureau \& Encarnação ${ }^{(3)}$ demonstrated that the expressing modes of EAA requirements have a significant impact on targets and recommendations of feed formulation.

Since the controversy arises from the different assumptions regarding the effects of $\mathrm{CP}$ and $\mathrm{DE}$ on EAA requirements, this issue can only be solved by elucidating whether CP or DE contents affect EAA requirement. Many studies have been published on lysine requirement of different fish species; however, investigations of the effect of dietary composition on lysine requirement have been scarce. In a quantitative

Abbreviations: \% diet, percentage of diet; \% protein, percentage of protein; AA, amino acid; BW, body weight; CP, crude protein; DE, digestible energy; EAA, essential amino acid; MBW, metabolic body weight; NRE, N retention efficiency. 
review, Hauler \& Carter $^{(4)}$ investigated intra-species variation in lysine requirement by examining the order of difference in published values (the percentage difference between the highest value and the lowest value). The study of Hauler \& Carter $^{(4)}$ suggests that it makes more sense to express lysine requirement as a ratio to DE than to express it as a percentage of dietary protein for fish. In recent years, several studies have examined the effect of dietary composition on lysine requirement. Encarnação et al. ${ }^{(5)}$ observed that DE levels did not affect lysine requirement in rainbow trout, suggesting that it is not appropriate to express lysine requirement in relation to $\mathrm{DE}$. On the other hand, an effect of $\mathrm{CP}$ on lysine requirement was observed in studies conducted with rainbow trout $^{(6,7)}$; these studies might be construed as evidence to support the argument of expressing lysine requirement as \% protein. At present, the controversy still remains and recent publication by the National Research Council ${ }^{(2)}$ opted to continue to express AA requirement as \% diet for want of a better alternative despite its significant limitations. It is therefore necessary to investigate the effect of dietary composition on lysine requirement in a systematic manner. Instead of examining these different factors one at a time through individual experiments, a meta-analytic mathematical modelling approach can be used to effectively integrate results from published studies. The body of literature data, especially the accelerated accumulation of published studies on different fish species during the past decades, provides a prime opportunity to use a modelling approach to delineate the effect of dietary factors, even though most of the studies in the literature did not specifically investigate the effect of dietary composition on lysine requirement. Furthermore, in a metaanalysis, it is important to account for the random effect of each study by using a mixed model approach instead of a fixed model approach, because each study represents a random sample of a larger population ${ }^{(8)}$. In the meantime, a meta-analysis can be viewed as a variant of multilevel analysis in which within-study and between-study effects are estimated $^{(9)}$

Therefore, the objective of the present study was to conduct non-linear mixed model analysis and multilevel analysis to investigate whether dietary $\mathrm{CP}$ and $\mathrm{DE}$ contents affect lysine requirement, i.e. whether lysine requirement of fish should be expressed as \% diet, \% protein or $\mathrm{g} / \mathrm{MJ} \mathrm{DE}$.

\section{Materials and methods}

\section{Modelling dataset}

A modelling dataset was established through a comprehensive literature review of studies on lysine requirement in fish. The modelling dataset included a total of forty-eight doseresponse studies on lysine requirement of thirty-four fish species published in the literature ${ }^{(5,6,10-55)}$. Since the objective of the present study was to investigate whether dietary CP or DE levels affect the estimates of lysine requirement, the dietary contents of CP and DE had to be either reported or could be estimated from diet compositions reported in these doseresponse studies; otherwise, studies were excluded from the modelling dataset. If necessary, DE contents were calculated when the gross energy content was reported and a digestibility coefficient of $85 \%$ was assumed; otherwise, energetic values of $23 \cdot 6,39 \cdot 5$ and $17 \cdot 2 \mathrm{~kJ} / \mathrm{g}$ and digestibility values of 90,95 and $70 \%$ were assumed for protein, lipid and carbohydrate, respectively ${ }^{(2,4)}$. The dataset encompassed a wide variety of diet compositions and lysine levels (Table 1). Dietary protein levels ranged from 24 to $55 \cdot 2 \%$, DE from $9 \cdot 8$ to $23 \mathrm{MJ} / \mathrm{kg}$ diet, and lysine from $0 \cdot 2$ to $7 \cdot 0 \%$ of diet. Weight gain is commonly used as a response criterion in dose-response studies of AA requirements, but increasingly protein gain is used as a response parameter as well ${ }^{(2)}$. Therefore, a sub-dataset was separated from the full dataset with protein gain as the response variable. The sub-dataset included twenty-eight studies that were conducted with twenty-one fish species. The sub-dataset is smaller than the full dataset due to two reasons: protein deposition had to be either reported in the studies or could be calculated based on the final and initial body compositions; protein deposition had to reach a plateau at the highest level of lysine tested in the experiments. Estimates of lysine requirement based on protein deposition may be higher than those based on weight gain $^{(2)}$; therefore, a plateau may be reached at the highest tested level of lysine when using weight gain as a response parameter but not when using protein deposition as a response parameter in some studies. Dietary protein levels ranged from 31.6 to $51.2 \%$, DE from 11.4 to $23.0 \mathrm{MJ} / \mathrm{kg}$ diet, and lysine from 0.2 to $7.0 \%$ of diet in the sub-dataset. Lysine deposition was not used as a response parameter in the present study because very few studies reported lysine deposition or lysine content in the fish body.

Table 1. Description of the datasets

(Mean, minimum and maximum values)

\begin{tabular}{|c|c|c|c|c|c|}
\hline & IBW (g) & Protein (\% diet) & $\mathrm{DE}(\mathrm{MJ} / \mathrm{kg})$ & Lys (\% diet) & $\begin{array}{l}\text { Requirement by the } \\
\text { broken-line model (\% diet) }\end{array}$ \\
\hline \multicolumn{6}{|l|}{ Full dataset* } \\
\hline Mean & $39 \cdot 7$ & $41 \cdot 4$ & $16 \cdot 9$ & $2 \cdot 0$ & 1.9 \\
\hline Minimum & 0.04 & 24.0 & $9 \cdot 8$ & 0.2 & $1 \cdot 1$ \\
\hline Maximum & 643 & $55 \cdot 2$ & $23 \cdot 0$ & $7 \cdot 0$ & $3 \cdot 1$ \\
\hline \multicolumn{6}{|l|}{ Sub-dataset† } \\
\hline Mean & $37 \cdot 2$ & $42 \cdot 3$ & 17.9 & $2 \cdot 1$ & $2 \cdot 0$ \\
\hline Minimum & 0.7 & $31 \cdot 6$ & $11 \cdot 4$ & 0.2 & $1 \cdot 2$ \\
\hline Maximum & 643 & $55 \cdot 2$ & $23 \cdot 0$ & $7 \cdot 0$ & 3.0 \\
\hline
\end{tabular}

IBW, initial body weight; DE, digestible energy.

${ }^{*}$ Dataset with body-weight gain as the response criterion.

†Dataset with protein deposition as the response criterion. 
Non-linear mixed model analysis when dietary lysine concentration is expressed as percentage of diet, percentage of protein or $\mathrm{g} / \mathrm{MJ}$ digestible energy

In the present study, four models commonly used to describe the nutrient requirement response of fish were fitted to the modelling datasets. These models are the broken-line model ${ }^{(56)}$, the exponential model ${ }^{(22)}$, the saturation kinetics model $^{(57)}$ and the four-parameter logistic model ${ }^{(58)}$. For the full dataset, the response variable was daily body-weight gain expressed as $\mathrm{g} / \mathrm{kg}$ metabolic body weight ( $\mathrm{MBW}, \mathrm{BW}^{08}$ ). For the sub-dataset, the response variable was $\mathrm{N}$ retention efficiency (NRE, \%). The independent variable was lysine concentration expressed as \% diet, \% protein or g/MJ DE.

The broken-line model is described as follows:

$$
y=L+U \times(R-x),
$$

where $y$ is the body-weight gain ( $\mathrm{g} / \mathrm{kg} \mathrm{MBW}$ per d) or NRE (\%); $x$, the lysine concentration (\% diet, $\%$ protein or $\mathrm{g} / \mathrm{MJ} \mathrm{DE}$ ); $L$, the ordinate of the breakpoint; $R$, the abscissa of the breakpoint; and $U$, the slope of the line for $x<R$. By definition, $(R-x)$ is zero when $x>R$.

The exponential model is described as follows:

$$
y=a\left(1-e^{-b(x-c)}\right),
$$

where $y$ is the body-weight gain ( $\mathrm{g} / \mathrm{kg}$ MBW per d) or NRE (\%); $x$, the lysine concentration (\% diet, $\%$ protein or $\mathrm{g} / \mathrm{MJ} \mathrm{DE}$ ); $a$, the plateau of the curve (upper asymptote); $b$, the parameter characterising the steepness of the curve; and $c$, the intercept on the $x$-axis.

The four-parameter logistic model is described as follows:

$$
y=\frac{a+(d(1+m)-a) e^{-k x}}{1+m e^{-k x}}
$$

where $y$ is the body-weight gain (g/kg MBW/d) or NRE (\%); $x$, the lysine concentration (\% diet, \% protein or g/MJ DE); $a$, the plateau of the curve (upper asymptote); $d$, the intercept on the $y$-axis; $k$, the scaling parameter that scales $x$; and $m$, the shaping parameter that locates the inflection point.

The saturation kinetics model is described as follows:

$$
y=\frac{d\left(k_{0.5}\right)^{n}+a x^{n}}{\left(k_{0.5}\right)^{n}+x^{n}}
$$

where $y$ is the body-weight gain ( $\mathrm{g} / \mathrm{kg} \mathrm{MBW}$ per d) or NRE (\%); $x$, the lysine concentration (\% diet, $\%$ protein or $\mathrm{g} / \mathrm{MJ} \mathrm{DE}$ ); $a$, the plateau of the curve (upper asymptote); $d$, the intercept on the $y$-axis; $k_{0.5}$, the concentration for $\frac{1}{2}$ of $(a+d)$; and $n$, the apparent kinetic order.

Data were analysed using the non-linear regression function of SAS software (version 9.1; SAS Institute). The mixed model procedure was used to consider the random effect of each study since the experiments represent a random sample of a larger population ${ }^{(8)}$. In the broken-line model, the random effect was added to parameters ' $L$ ' and ' $U$ ', which allowed accounting for between-study heterogeneity in maximum response and the steepness of response to AA intakes ${ }^{(59)}$. In the exponential model, the random effect was added to parameters ' $a$ ' and ' $c$ ', which allowed accounting for between-study heterogeneity in maximum response and the intercept on the $x$-axis ${ }^{(60)}$. Similarly, the random effect was added to parameters ' $a$ ' and ' $d$ ' in the four-parameter logistic model and the saturation kinetics model to allow accounting for between-study heterogeneity in maximum response and the intercept on the $y$-axis. Due to the limited size of the datasets, the random effect was not simultaneously added to more than two parameters to avoid undue model complexity and over-fitting of the data with an excess of random effects.

The goodness of fit of the models was evaluated by the corrected Akaike information criteria ${ }^{(61)}$. A smaller value indicates a better fit. The goodness of fit was compared for lysine concentration expressed as \% diet, \% protein or g/MJ DE. A better fit to the response curves was considered as a more appropriate way of expressing lysine requirement.

\section{Multilevel analysis}

A multilevel analysis was further conducted to investigate the effects of dietary CP and DE on lysine requirement. Meta-analysis can be viewed as a special case of multilevel analysis ${ }^{(9)}$. The following procedure for multilevel analysis was performed according to $\operatorname{Hox}^{(62)}$ : (1) a baseline (null) model that included only the intercept was first computed (the baseline model assumed that lysine requirement should be expressed as \% diet), (2) explanatory variables (CP and DE) were included in the model, and then (3) a $\chi^{2}$ difference test was conducted to examine whether the model with explanatory variables had a significantly better fit than the baseline model. Subsequently, non-significant fixed-effect variables were dropped, and the multilevel analysis was re-run.

The multilevel meta-analysis model is a linear mixed-effect model that takes into account the random effect of each study, which can be written as follows:

$$
y_{j}=\gamma_{0}+\gamma_{1} x_{1 j}+\gamma_{2} x_{2 j}+u_{j}+e_{j},
$$

where $y_{j}$ is the lysine requirement estimate (\% diet) from the $j$ th study; $\gamma$, the study-level fixed-effect regression coefficients; $x$, the fixed-effect explanatory variables (CP and DE); $u_{j}$, the study-level random error; $e_{j}$, the sampling error in the jth study.

In addition to dietary factors, biological factors such as body weight may also affect lysine requirement. Therefore, subsequent to dietary factors, a multilevel analysis was further carried out by adding body weight of fish as a fixed-effect explanatory variable to the multilevel model. Because the majority of studies in the modelling dataset were conducted with juvenile fish and the distribution of body weights was skewed, initial body weights of fish from each study were log-transformed to achieve a normal distribution.

It is known that mathematical models chosen to fit the response curve affect requirement estimates. Therefore, to ensure the comparability of the lysine requirement estimates across studies in the multilevel analysis, the estimates had to be obtained using the same dose-response model. In the present study, the broken-line model was chosen to obtain the requirement estimates for all studies. 
The multilevel analysis was carried out using the linear mixed-effects procedure of SAS software (version 9.1; SAS Institute)

\section{Results}

Non-linear mixed model analysis when dietary lysine concentration is expressed as percentage of diet, percentage of protein, or g/MJ digestible energy

Tables 2 and 3 present the comparisons of the goodness of fit to the modelling dataset when lysine concentration was expressed as \% diet, \% protein or $\mathrm{g} / \mathrm{MJ} \mathrm{DE}$ for body-weight gain as the response variable, and for NRE as the response variable, respectively. The results suggest that irrespective of the response criteria, expressing lysine concentration as $\%$ protein gave the lowest corrected Akaike information criteria values, indicating the best fit to the modelling data. It appears that expressing lysine concentration as \% protein provides a better goodness of fit to the modelling dataset than expressing it as \% diet, which in turn is generally better than expressing it as $\mathrm{g} / \mathrm{MJ} \mathrm{DE}$. The results also indicate that the best-fit mathematical model may differ depending on the assessed response variables. The saturation kinetics model was the best-fit model when the response variable was bodyweight gain, whereas the exponential model was the best-fit model when the response variable was protein deposition.

Table 4 presents the estimates of lysine requirement by different mathematical models according to different expressing modes and response criteria. It appears that mathematical models greatly affect the estimates of lysine requirement. Irrespective of the mode of expressing lysine requirement or the response variable, the broken-line model yielded the lowest estimates. The highest estimates were dependent on the response variable: the exponential model yielded the highest estimates when the response variable was bodyweight gain, whereas saturation kinetics yielded the highest estimates when the response variable was NRE. Differences between the highest and the lowest values across different mathematical models vary from 36 to $91 \%$. Response variables also affected the estimates of lysine requirement. In general, estimates were higher when using NRE as the response variable than those when using body-weight gain as the response variable. Moreover, the magnitude of difference between the results from two response variables was affected by mathematical models. When comparing the estimates obtained by using the two response criteria, the differences were relatively

Table 2. Goodness of fit* when lysine concentration was expressed as \% diet, \% protein or $\mathrm{g} / \mathrm{MJ}$ digestible energy (DE) and the response variable was expressed as bodyweight gain ( $\mathrm{g} / \mathrm{kg}$ metabolic body weight per $\mathrm{d}$ )

\begin{tabular}{lrrr}
\hline Models & $\%$ Diet & \% Protein & \multicolumn{1}{c}{ g/MJ DE } \\
\hline Broken-line & 1134.9 & $1079 \cdot 2$ & 1210.4 \\
Exponential & 1137.0 & 1097.4 & 1121.4 \\
Logistic & 1059.4 & 988.1 & 1095.5 \\
Saturation kinetics & 1046.5 & 981.0 & $1066 \cdot 1$ \\
\hline
\end{tabular}

* Selection criteria: corrected Akaike information criteria; smaller values are better.
Table 3. Goodness of fit* when lysine concentration was expressed as \% diet, \% protein, or g/MJ digestible energy (DE) and the response variable was expressed as nitrogen retention efficiency

\begin{tabular}{lccc}
\hline Models & \% Diet & \% Protein & g/MJ DE \\
\hline Broken-line & 1438.6 & 1404.6 & 1496.9 \\
Exponential & 1385.4 & $1368 \cdot 1$ & $1385 \cdot 1$ \\
Logistic & 1394.3 & 1368.4 & 1419.0 \\
Saturation kinetics & 1398.7 & $1377 \cdot 1$ & 1418.0 \\
\hline
\end{tabular}

* Selection criteria: corrected Akaike information criteria; smalle values are better.

small (below 15\%) for the broken-line model and the exponential model, between 25 and $32 \%$ for the logistic model, but as high as $50 \%$ for the saturation kinetics model.

\section{Multilevel analysis}

Table 5 presents the results from the multilevel analysis. The null model represents the assumption that lysine requirement should be expressed as \% diet. This null model could not be rejected in favour of the alternative model with both $\mathrm{CP}$ and DE. In addition, the coefficient of the variable DE in the multilevel model with CP and DE was not statistically significant from zero. Therefore, the variable DE was dropped from the multilevel model, and this resulted in the alternative model with $\mathrm{CP}$ only. The mixed model analysis was then re-run on the alternative model with CP. Results from the $\chi^{2}$ test on the deviance difference between the null model and the multilevel model with CP suggested that the null model could be rejected in favour of the multilevel model with $\mathrm{CP}$, and the effect of $\mathrm{CP}$ was statistically significant $(P<0.05)$. Multilevel analyses on the full dataset and the sub-dataset yielded the same results, suggesting that $\mathrm{CP}$ had a significant effect on lysine requirement irrespective of the response criteria (weight gain or protein deposition) in assessing lysine requirement. A further multilevel analysis was carried out with logtransformed initial body weights as a fixed effect being added onto the multilevel model with CP. The coefficient of the variable $\log \mathrm{BW}$ in the resulted multilevel model was not statistically significant from zero. This lack of the effect from body weight was observed irrespective of whether weight gain or protein deposition was used as a response variable. Overall, results from the multilevel analysis suggest that $\mathrm{CP}$ had a significant effect on lysine requirement, whereas DE or BW did not appear to affect lysine requirement in the present study.

\section{Discussion}

Different modes of expressing AA requirement have been proposed and used in the fish nutrition literature, namely $\%$ diet, $\%$ protein or $\mathrm{g} / \mathrm{MJ} \mathrm{DE}$. Controversy arises from the fact that each mode can find support on theoretical and experimental bases $^{(2,3)}$. The present study analysed these modes of expression from a quantitative meta-analysis perspective. While it is difficult to investigate various factors in a single experiment, the meta-analysis provides an effective approach to integrate and synthesise experimental observations from 
Table 4. Estimates of lysine requirement by different modes of expression, response variables and mathematical models

\begin{tabular}{|c|c|c|c|c|c|c|c|c|c|}
\hline \multirow{2}{*}{$\begin{array}{l}\text { Expression modes... } \\
\text { Response variables }\end{array}$} & \multicolumn{3}{|c|}{$\%$ Diet } & \multicolumn{3}{|c|}{$\%$ Protein } & \multicolumn{3}{|c|}{ g/MJ DE } \\
\hline & Weight gain & NRE & Difference (\%) & Weight gain & NRE & Difference (\%) & Weight gain & NRE & Difference (\%) \\
\hline Broken-line & 1.66 & 1.70 & $2 \cdot 4$ & 4.55 & 4.84 & $6 \cdot 4$ & 0.89 & 1.01 & 13.5 \\
\hline Exponential & 2.47 & $2 \cdot 73$ & $10 \cdot 5$ & $6 \cdot 19$ & 7.02 & 13.4 & $1 \cdot 28$ & 1.39 & $8 \cdot 6$ \\
\hline Logistic & 1.79 & 2.37 & $32 \cdot 4$ & 4.64 & $5 \cdot 81$ & $25 \cdot 2$ & 1.06 & 1.40 & $32 \cdot 1$ \\
\hline Saturation kinetics & 2.03 & $3 \cdot 16$ & $55 \cdot 7$ & $5 \cdot 18$ & $7 \cdot 65$ & $47 \cdot 7$ & 1.26 & 1.93 & $53 \cdot 2$ \\
\hline
\end{tabular}

$D E$, digestible energy; NRE, $N$ retention efficiency.

different studies. The present study carried out non-linear mixed model analysis and multilevel analysis to investigate the effects of dietary CP and DE on lysine requirement in order to identify the best way of expressing lysine requirement for fish.

Through the non-linear mixed model analysis, the present study found that the best goodness of fit to the modelling data was produced when lysine concentration was expressed as a percentage of dietary protein. The multilevel analysis further confirmed that dietary DE level did not affect lysine requirement, but $\mathrm{CP}$ content did; lysine requirement (\% diet) increases with dietary protein level. Therefore, the results of the present study suggest that it is more appropriate to express lysine requirement as \% protein than to express it as \% diet or $\mathrm{g} / \mathrm{MJ} \mathrm{DE}$. In fish nutrition, the limitations of the common practice of expressing AA requirement as a fixed concentration of diet have been recognised, but whether to express AA requirement as $\%$ protein or $\mathrm{g} / \mathrm{MJ}$ DE remains difficult to resolve $^{(2)}$. To relate AA requirement to $\mathrm{DE}$ content of the diet in fish nutrition is based on the assumption that DE determines feed intake (and consequently AA intake); therefore, dietary AA levels should be adjusted according to dietary DE levels to maintain the AA intake ${ }^{(2,22,63)}$. This mode of expression has also been found valid in pig nutrition based on the well-documented relationship between energy and protein supply on protein deposition ${ }^{(64-69)}$. In pigs, it has been well established that dietary energy supply affects AA requirement, but not the efficiency of AA utilisation; therefore, $\mathrm{AA}$ requirement is specific to a given energy level ${ }^{(67-71)}$. In poultry, recommendations on AA requirements can also be found as a ratio to dietary energy ${ }^{(72,73)}$, but this mode of expression has been disputed by some studies ${ }^{(74,75)}$. Experimentation with rainbow trout has revealed that dietary DE levels affected the marginal lysine utilisation efficiency ${ }^{(5)}$. Similar effects of dietary energy content have also been observed on methionine and leucine utilisation in steers ${ }^{(76,77)}$. Results from these studies indicate that different farmed animals may differ in the relationship between energy supply and AA requirement/utilisation. The present study agrees with the experimental findings in fish that there is a lack of the effect of DE levels on lysine requirement and it is not appropriate to express lysine requirement as a ratio to $\mathrm{DE}^{(2,5)}$.

In poultry, a number of studies have provided strong argument to relate AA requirement to dietary protein ${ }^{(74,78-81)}$ In fish, estimates of AA requirement expressed as \% protein can also be found in the literature ${ }^{(82,83)}$. This mode of expression implies that dietary protein supply affects AA requirement, but does not affect the marginal AA utilisation efficiency. A few studies have investigated the effect of dietary protein on AA requirement or utilisation efficiency. Lysine utilisation appeared to be lower when rainbow trout were fed diets containing 35\% dietary protein compared with $55 \%$ dietary protein, but the difference was not statistically significant ${ }^{(84)}$. A study conducted with Atlantic salmon fry also found a slight but non-significant increase in lysine retention efficiency by a high-protein $\operatorname{diet}^{(85)}$. Although not statistically significant, these results may be construed as evidence against expressing lysine requirement as \% protein. Conversely, some studies observed that protein levels affected

Table 5. Results of the multilevel analysis

\begin{tabular}{|c|c|c|c|c|c|c|c|c|c|}
\hline & \multicolumn{2}{|c|}{ Intercept } & \multicolumn{2}{|c|}{$\mathrm{CP}$} & \multicolumn{2}{|c|}{$\mathrm{DE}$ or $\log \mathrm{BW}$} & \multicolumn{3}{|c|}{$\chi^{2}$ test $^{*}$} \\
\hline & Coefficient & $P$ & Coefficient & $P$ & Coefficient & $P$ & Deviance difference & df & $P$ \\
\hline \multicolumn{10}{|l|}{ Full dataset $\dagger$} \\
\hline Null model & 1.860 & $<0.0001$ & - & - & - & - & - & - & - \\
\hline Multilevel model with $\mathrm{CP}$ and $\mathrm{DE}$ & 0.853 & 0.014 & 0.033 & $<0.001$ & -0.021 & 0.291 & $1 \cdot 1$ & 2 & 0.577 \\
\hline Multilevel model with CP & 0.692 & 0.024 & 0.028 & $<0.001$ & - & - & $5 \cdot 9$ & 1 & 0.015 \\
\hline $\begin{array}{l}\text { Multilevel model with CP and log } \\
\text { BW }\end{array}$ & 0.715 & 0.023 & 0.028 & $<0.001$ & -0.014 & 0.617 & 0.9 & 2 & 0.638 \\
\hline \multicolumn{10}{|l|}{ Sub-dataset $\ddagger$} \\
\hline Null model & 1.964 & $<0.0001$ & - & - & - & - & - & - & - \\
\hline Multilevel model with $\mathrm{CP}$ and $\mathrm{DE}$ & 0.467 & 0.303 & 0.046 & $<0.0001$ & -0.025 & 0.231 & 3.5 & 2 & 0.174 \\
\hline Multilevel model with $\mathrm{CP}$ & 0.207 & 0.604 & 0.041 & 0.0001 & - & - & 7.9 & 1 & $<0.005$ \\
\hline $\begin{array}{l}\text { Multilevel model with CP and log } \\
\text { BW }\end{array}$ & 0.272 & 0.489 & 0.038 & 0.0005 & 0.054 & 0.141 & $5 \cdot 3$ & 2 & 0.071 \\
\hline
\end{tabular}

$\mathrm{CP}$, crude protein; $\mathrm{DE}$, digestible energy; $\mathrm{BW}$, body weight.

${ }^{\star} \chi^{2}$ test on the deviance difference between the multilevel models and the null models.

†Dataset with body-weight gain as the response criterion.

$\ddagger$ Dataset with protein deposition as the response criterion. 
lysine requirement, but not marginal lysine utilisation efficiency in rainbow trout fry ${ }^{(6,7)}$. The study of Nang Thu et $a{ }^{\left({ }^{(7)}\right.}$ also observed that fish appear to regulate their feed consumption based on protein intake for potential protein deposition rather than energy intake, an observation that is in agreement with several other studies ${ }^{(5,86,87)}$. Results from these studies indicate that lysine requirement should be expressed as \% protein. Therefore, it appears that there is conflicting experimental evidence regarding expressing lysine requirement as a percentage of dietary protein in the literature. The results from the present study lend support to the argument to relating AA requirement to dietary protein from a quantitative meta-analysis perspective. Future research is warranted to shed more light on this topic. In any case, one should heed the limitations associated with this mode of expression: the possible underestimate of $\mathrm{AA}$ requirement due to excessive protein and the lack of reflection of true protein composition by $\mathrm{CP}^{(2)}$.

The present study disagrees in part with a previous quantitative review by Hauler \& Carter $^{(4)}$, which suggested that it makes more sense to express lysine requirement as a ratio to DE than to express it as a percentage of dietary protein for fish. Differences exist between the present study and the study of Hauler \& Carter ${ }^{(4)}$. The modelling dataset in the present study encompasses a broad number of studies and over half of these studies were published during the last decade, reflecting the latest information on lysine nutrition in fish. The present study also conducted separate analyses based on the response criteria of body-weight gain and protein deposition. It is known that different response criteria result in different AA requirement estimates ${ }^{(2)}$; therefore, separate analyses eliminate the confounding effect of response criteria. Furthermore, the present study employed two approaches (non-linear mixed model analysis and multilevel analysis) to quantitatively integrate and synthesise results from published studies, and the results from these two modelling approaches corroborate with each other. To account for the random effect of each study is particularly important for using a modelling approach to quantitatively integrate and synthesise results from different studies, because each study represents a random sample of a larger population ${ }^{(8)}$. This allows accounting for between-study heterogeneity ${ }^{(8)}$. In addition to dietary composition, other factors such as body size or life stage of fish, experimental condition and mathematical models used to derive the requirement may be associated with the variation of lysine requirements ${ }^{(2)}$. In the present study, mixed model analysis and multilevel analysis considered dietary factors as the fixed effect, and other factors as the random effect; these approaches effectively delineated the effect of dietary factors from other factors that contribute to the variation of lysine requirement estimates.

Mathematical models used in fitting the dose-response curve in requirement studies have been found to influence the estimates of nutrient requirement ${ }^{(2)}$. Indeed, there are considerable differences among lysine requirement estimates by the four non-linear models in the present study. Adding to this complexity is that estimates of lysine requirement also differ greatly according to the response criteria (body weight gain $v$. protein deposition). Estimates obtained from protein deposition were higher than those from body-weight gain, which agrees with literature findings ${ }^{(2,22)}$. This present study, however, further quantified the differences between the estimates obtained from different response variables and found these differences were dependent on different mathematical models: the differences were relatively small (below 15\%) for the broken-line model and the exponential model, between 25 and $32 \%$ for the logistic model, but as high as $50 \%$ for the saturation kinetics model. Irrespective of the mode of expressing lysine requirement or the response variable, the broken-line model yielded the lowest estimates. This is in agreement with literature reports that the brokenline model tends to underestimate nutrient requirement ${ }^{(88-90)}$. Furthermore, the present study established that the highest estimates were dependent on the response variable: the exponential model yielded the highest estimate when the response variable was body-weight gain, whereas saturation kinetics yielded the highest estimate when the response variable was NRE. The best-fit model is also dependent on response criteria. The present study identified that the saturation kinetics model was the best-fit model when the response variable was body-weight gain, whereas the exponential model was the best-fit model when the response variable was protein deposition efficiency. These results demonstrate the importance of specifying the chosen response criteria and mathematical models when reporting AA requirement estimates. Meaningful comparison of requirements from different studies can only be made on estimates produced by the same model. Consequently, in the present study, the multilevel analysis was carried out on lysine requirements estimated by the same model (the broken-line model) from different studies. Although the broken-line model may underestimate the actual requirement, it is inconsequential to the multilevel analysis. This is because the objective of the multilevel analysis was to test the dietary effect on lysine requirement on a comparable basis. The benefit of choosing the broken-line model is that it yields unequivocal requirement estimates as well as standard errors of the estimates, which are required by the multilevel analysis. In contrast, standard errors of requirement estimates are not produced by the other non-linear models. In the present study, results from the multilevel analysis and the non-linear mixed model analysis strongly corroborate with each other; results from both approaches support expressing lysine requirement as \% protein for fish.

The present study focused on investigating dietary factors that affect lysine requirement. Other factors, such as biological factors (life stages or fish species), may also affect lysine requirement. Fish size could be an important factor in assessing AA utilisation and requirement. It is known that protein requirement decreases as fish grow, and thus it is likely that AA requirement also decreases with fish body weight ${ }^{(2)}$. However, so far, this has not been substantiated by direct experimental evidences. Most studies on lysine requirement have been carried out on juvenile fish, and there are very few data on fish of medium and large sizes. In the present study, the multilevel analysis was employed as an attempt to delineate the effect of body weight on lysine requirement. Results 
from the analysis appear to suggest a non-significant effect of body weight. The aforementioned lack of sufficient data on medium- and large-sized fish may have limited the scope of the analysis in the present study and consequently these results should be viewed as inconclusive. Differences among fish species might exist ${ }^{(2)}$, although it has been argued that lysine requirement is relatively homogeneous across fish species $^{(91)}$. However, the delineation and quantification of species effect are currently hindered by the limited data available on different fish species in the literature. Even though many studies have been conducted on lysine requirement, these studies spread over different species and thus the numbers of studies for each fish species are very limited. Since the objective of the present study was to find out the most appropriate mode of expressing lysine requirement, the pertinent issue is whether the most appropriate mode differs among fish species. Currently, there is no evidence to suggest that it differs. Therefore, in the present study, differences among species were ascribed to but not specifically differentiated from the between-study heterogeneity. The issues of fish species and life stages can be revisited in the future when there are a sufficient number of studies conducted with each fish species at different life stages to allow a proper quantitative evaluation.

The present study investigated the three modes of expressing EAA requirements commonly used by fish nutritionists. These modes are based on dietary inclusion levels. In practice, it is also possible to express lysine requirement as daily intake. Screening studies based on feed intake information would result in a significant reduction of sample size of the modelling datasets. Studies have to be excluded in the case where no information on feed intake was reported, where fish were fed to an excess or fixed amount but there was no report on whether the feeds were all consumed by fish or whether measures were taken to account for the feed wastage. Since the objective was to compare the three common methods of expressing lysine requirement and to investigate the underlying dietary factors that affect lysine requirement of fish, the option of expressing lysine requirement as daily intake was not assessed in the present meta-analysis.

It has been advocated that AA studies should move away from dose-response experiments to those striving to investigate the cause-effect relationship ${ }^{(1)}$. Increasingly, factorial models are being used to predict AA requirement ${ }^{(2)}$. The factorial approach is based on the information on maintenance requirement and AA deposition for body protein and its utilisation efficiency. A step further is to estimate AA requirements by mechanistic growth and nutrient partitioning models that take into account maintenance, deposition, inevitable and preferential AA metabolism ${ }^{(2,92)}$. EAA requirements can thus be dynamic and flexible based on the response of fish to a specific dietary composition to achieve a certain performance at a defined life stage. This would effectively incorporate both dietary factors and biological factors in estimating lysine requirement. In factorial and mechanistic models, AA requirements can be expressed as $\mathrm{mg} / \mathrm{d}, \mathrm{mg} / \mathrm{kg} \mathrm{BW}$ per $\mathrm{d}$ or $\mathrm{mg} / \mathrm{kg}$ MBW per $\mathrm{d}$, taking feed intake into account. Discussions on developing factorial or mechanistic models are beyond the scope of the present study. Nevertheless, to express AA requirement as \% diet, \% protein or g/MJ DE is simple, straightforward and will probably continue to be used in feed formulation, as one can find in the nutrient requirement tables published by the $\mathrm{NRC}^{(2)}$. The present study suggests that the current practice adopted by most fish nutritionists to express requirement as a fixed concentration of diet provides less goodness of fit than to express requirement as a percentage of dietary protein, but is generally better than to express requirement as a ratio to DE content.

\section{Acknowledgements}

K. H. is a junior professor at Humboldt-Universität zu Berlin, Germany, and is the sole author of the paper. The author has no conflict of interest to declare.

\section{References}

1. Moughan PJ \& Fuller MF (2003) Modelling amino acid metabolism and the estimation of amino acid requirements. In Amino Acids in Animal Nutrition, 2nd ed., pp. 187-202 [JPF D'Mello, editor]. Wallingford: CABI Publishing.

2. NRC (National Research Council) (2011) Nutrient Requirements of Fish and Shrimp. Washington, DC: National Academy Press.

3. Bureau DP \& Encarnação PM (2006) Adequately determining the amino acid requirements of fish: the case example of lysine. In Avances en Nutricion Acuicola, VIII Simposium Internacional de Nutricion Acuicola (Advances in Aquaculture Nutrition, VIII International Symposium on Aquaculture Nutrition), 15-17 November 2006, Universidad Autónoma de Nuevo León, Mexico, pp. 29-54 [LE Cruz-Suarez, D Ricque-Marie, M Tapia-Salazar, MG Nieto-Lopez, DA Villareal Cavazos, AC Puello Cruz and A Garcia-Ortega, editors]. Nuevo León: Universidad Autónoma de Nuevo León.

4. Hauler RC \& Carter CG (2001) Re-evaluation of the quantitative dietary lysine requirements of fish. Rev Fish Sci 9, 133-163.

5. Encarnação P, de Lange C, Rodehutscord M, et al. (2004) Diet digestible energy content affects lysine utilization, but not dietary lysine requirements of rainbow trout (Oncorbynchus mykiss) for maximum growth. Aquaculture 235, 569-586.

6. Bodin N, Govaerts B, Abboudi T, et al. (2009) Protein level affects the relative lysine requirement of growing rainbow trout (Oncorbynchus mykiss) fry. Br J Nutr 102, 37-53.

7. Nang Thu TT, Parkouda C, de Saeger S, et al. (2009) Protein level does not affect lysine utilization efficiency at marginal lysine intake in growing rainbow trout (Oncorbynchus mykiss) fry. Aquaculture 288, 312-320.

8. St-Pierre NR (2001) Integrating quantitative findings from multiple studies using mixed model methodology. J Dairy Sci 84, 741-755.

9. Hox JJ \& de Leeuw ED (2003) Multilevel models for metaanalysis. In Multilevel Modeling. Methodological Advances, Issues, and Applications, pp. 90-111 [SP Reise and N Duan, editors]. Mahwah, NJ: Lawrence Erlbaum Associates.

10. Wilson RP, Hardin DE \& Garling DL (1977) Effect of dietary $\mathrm{pH}$ on amino acid utilization and the lysine requirement of fingerling channel catfish. J Nutr 104, 166-170.

11. Robinson EH, Wilson RP \& Poe WE (1980) Re-evaluation of the lysine requirement and lysine utilization by fingerling channel catfish. J Nutr 110, 2313-2316. 
12. Walton MJ, Cowey CB \& Adron JW (1984) The effect of dietary lysine levels on growth and metabolism of rainbow trout (Salmo gairdneri). BrJ Nutr 52, 115-122.

13. Akiyama T, Arai S, Murai T, et al. (1985) Threonine, histidine and lysine requirements of chum salmon fry. Bull Jpn SOC Sci Fish 51, 635-639.

14. Santiago CB \& Lovell RT (1988) Amino-acid requirements for growth of Nile tilapia. J Nutr 118, 1540-1546.

15. Borlongan IG \& Benitez LV (1990) Quantitative lysine requirement of milkfish (Chanos chanos) juveniles. Aquaculture 87, 341-347.

16. Tibaldi E \& Lanari D (1991) Optimal dietary lysine levels for growth and protein utilisation of fingerling sea bass (Dicentrarchus Labrax L.) fed semipurified diets. Aquaculture 95, 297-304.

17. Craig SR \& Gatlin DM (1992) Dietary lysine requirement of juvenile red drum Sciaenops ocellatus. J World Aquacult Soc 23, 133-137.

18. Griffin ME, Brown PB \& Grant AL (1992) The dietary lysine requirement of juvenile hybrid striped bass. J Nutr 122, $1332-1337$.

19. Keembiyehetty CN \& Gatlin DM III (1992) The dietary lysine requirement of juvenile striped bass (Morone chrysops X $M$. saxatilis). Aquaculture 104, 271-277.

20. Kim KI, Kayes TB \& Amundson CH (1992) Requirements for lysine and arginine by rainbow trout (Oncorbynchus mykiss). Aquaculture 106, 333-344.

21. Anderson JS, Lall SP, Anderson DM, et al. (1993) Quantitative dietary lysine requirement of Atlantic salmon (Salmo salar) fingerlings. Can J Fish Aquat Sci 50, 316-322.

22. Rodehutscord M, Becker A, Pack M, et al. (1997) Response of rainbow trout (Oncorbynchus mykiss) to supplements of individual essential amino acids in a semipurified diet, including an estimate of the maintenance requirement for essential amino acids. $J$ Nutr 127, 1166-1175.

23. Ruchimat T, Masumoto T, Hosokawa H, et al. (1997) Quantitative lysine requirement of yellowtail (Seriola quinqueradiata). Aquaculture 158, 331-339.

24. Fagbenro OA, Balogun AM, Fasakin EA, et al. (1998) Dietary lysine requirement of the African catfish, Clarias gariepinus. J Appl Aquacult 8, 71-77.

25. Forster I \& Ogata HY (1998) Lysine requirement of juvenile Japanese flounder Paralichthys olivaceus and juvenile red sea bream Pagrus major. Aquaculture 161, 131-142.

26. Berge GE, Sveier H \& Lied E (1999) Nutrition of Atlantic salmon (Salmo salar); the requirement and metabolic effect of lysine. Comp Biochem Physiol 120A, 477-485.

27. Small BC \& Soares JH Jr. (2000) Estimating the quantitative essential amino acid requirements of striped bass Morone saxatilis, using fillet A/E ratios. Aquacult Nutr 4, 225-232.

28. Murillo-Gurrea DP, Coloso RM, Borlongan IG, et al. (2001) Lysine and arginine requirements of juvenile Asian sea bass (Lates calcarifer). J Appl Ichthyol 17, 49-53.

29. Tantikitti C \& Chimsung N (2001) Dietary lysine requirement of freshwater catfish (Mystus nemurus Cuv. \& Val.). Aquacult Res 32, 135-141.

30. Kim JD \& Lall SP (2003) Dietary lysine requirement of juvenile yellowtail flounder Pleuronectes ferrugineus. Asian Austral J Anim 16, 1777-1781.

31. Ahmed I \& Khan MA (2004) Dietary lysine requirement of fingerling Indian major carp, Cirrbinus mrigala (Hamilton). Aquaculture 235, 499-511.

32. Furuya WM, Botaro D, Neves PR, et al. (2004) Lysine requirement of Nile tilapia (Oreochromis niloticus), during the grow-out phase. Cienc Rural 34, 1571-1577.
33. Furuya WM, dos Santos VG, Silva LCR, et al. (2006) Digestible lysine requirements of Nile tilapia juveniles. Rev Bras Zootec 35, 937-942.

34. Wang S, Liu YJ, Tian LX, et al. (2005) Quantitative dietary lysine requirement of juvenile grass carp Ctenopharyngodon idella. Aquaculture 249, 419-429.

35. Wang S, Encarnacao PM, Payne RL, et al. (2010) Estimating dietary lysine requirements for live weight gain and protein deposition in juvenile rainbow trout (Oncorhynchus mykiss). In 14th International Symposium on Fish Nutrition and Feeding, 31 May-4 June 2010, Qingdao, China.

36. Luo Z, Liu YJ, Mai KS, et al. (2006) Quantitative L-lysine requirement of juvenile grouper Epinephelus coioides. Aquacult Nutr 12, 165-172.

37. Mai KS, Lu Z, Ai QH, et al. (2006) Dietary lysine requirement of juvenile Japanese seabass, Lateolabrax japonicas. Aquaculture 258, 535-542.

38. Marcouli PA, Alexis MN, Andriopoulou A, et al. (2006) Dietary lysine requirement of juvenile gilthead seabream Sparus aurata L. Aquacult Nutr 12, 25-33.

39. Montes-Girao PJ \& Fracalossi DM (2006) Dietary lysine requirement as basis to estimate the essential dietary amino acid profile for jundiá, Rhamdia quelen. $J$ World Aquacult Soc 37, 388-396

40. Dairiki JK, dos Santos Dias CT \& Cyrino JEP (2007) Lysine requirements of largemouth bass, Micropterus salmoides: a comparison of methods of analysis of dose-response trials data. J Appl Aquac 19, 1-27.

41. Espe M, Lemme A, Petri A, et al. (2007) Assessment of lysine requirement for maximal protein accretion in Atlantic salmon using plant protein diets. Aquaculture 263, 168-178.

42. Nang Thu TT, Parkouda C, Saeger SD, et al. (2007) Comparison of the lysine utilization efficiency in different plant protein sources supplemented with L-lysine. $\mathrm{HCl}$ in rainbow trout (Oncorbynchus mykiss) fry. Aquaculture 272, 477-488.

43. Zhou QC, Wu ZH, Chi SY, et al. (2007) Dietary lysine requirement of juvenile cobia (Rachycentron canadum). Aquaculture 273, 634-640.

44. Zhou XQ, Zhao CR, Jiang J, et al. (2008) Dietary lysine requirement of juvenile Jian carp (Cyprinus carpio var. Jian). Aquacult Nutr 14, 381-386.

45. Zhou F, Shao J, Xu R, et al. (2010) Quantitative L-lysine requirement of juvenile black sea bream (Sparus macrocephalus). Aquacult Nutr 16, 194-204.

46. Peres H \& Oliva-Teles A (2008) Lysine requirement and efficiency of lysine utilization in turbot (Scophthalmus maximus) juveniles. Aquaculture 275, 283-290.

47. Zhang C, Ai Q, Mai K, et al. (2008) Dietary lysine requirement of large yellow croaker, Pseudosciaena crocea R. Aquaculture 283, 123-127.

48. Bicudo ÁJA, Sado RY \& Cyrino JEP (2009) Dietary lysine requirement of juvenile pacu Piaractus mesopotamicus (Holmberg, 1887). Aquaculture 297, 151-156.

49. Abidi SF \& Khan MA (2010) Growth, protein retention, and body composition of fingerling Indian major carp, rohu, Labeo rohita (Hamilton), fed diets with various levels of lysine. J World Aquacult Soc 41, 791-799.

50. Abimorad EG, Favero GC, Squassoni GH, et al. (2010) Dietary digestible lysine requirement and essential amino acid to lysine ratio for pacu Piaractus mesopotamicus. Aquacult Nutr 16, 370-377.

51. Deng DF, Dominy WG, Ju ZY, et al. (2010) Dietary lysine requirement of juvenile Pacific threadfin (Polydactylus sexfilis). Aquaculture 308, 44-48.

52. Grisdale-Helland B, Gatlin DM, Corrent E, et al. (2010) The minimum dietary lysine requirement, maintenance 
requirement and efficiency of lysine utilization for growth of Atlantic salmon smolts. Aquacult Res 42, 1509-1529.

53. Khan MA \& Abidi SF (2011) Effect of dietary L-lysine levels on growth, feed conversion, lysine retention efficiency and haematological indices of Heteropneustes fossilis (Bloch) fry. Aquacult Nutr 17, E657-E667.

54. Masagounder K, Hayward RS \& Firman JD (2011) Comparison of dietary essential amino acid requirements determined from group-housed versus individually-housed juvenile bluegill, Lepomis macrochirus. Aquacult Nutr 17, E559-E571.

55. Yang JL, Wang CA, Xu H, et al. (2011) Requirement of essential amino acids for Hucho taimen juvenile. J Fish China 34, $565-571$.

56. Robbins KR, Norton HW \& Baker DH (1979) Estimation of nutrient requirements from growth data. J Nutr 109, 1710-1714.

57. Mercer LP (1982) The quantitative nutrient-response relationship. J Nutr 112, 560-566.

58. Gahl MJ, Finke MD, Crenshaw TD, et al. (1991) Use of a four-parameter logistic equation to evaluate the response of growing rats to ten levels of each indispensable amino acid. J Nutr 121, 1720-1729.

59. Robbins KR, Saxton AM \& Southern LL (2006) Estimation of nutrient requirements using broken-line regression analysis. J Anim Sci 84, E155-E165.

60. Hua K (2011) Estimating maintenance amino acids requirements of fish through a nonlinear mixed modelling approach. Aquacult Res (In the Press).

61. Burnham KP \& Anderson DR (2002) Model Selection and Multimodel Inference: A Practical Information-Theoretic Approach, 2nd ed. New York, NY: Springer-Verlag.

62. Hox JJ (1995) Applied Multi-level Analysis, 2nd ed. Amsterdam: TT-Publikaties.

63. Pfeffer E, Al-Sabty H \& Haverkamp R (1992) Studies on lysine requirements of rainbow trout (Oncorbynchus mykiss) fed wheat gluten as only source of dietary protein. J Anim Physiol Anim Nutr 67, 74-82.

64. Campbell RG, Taverner MR \& Curic DM (1983) The influence of feeding level from 20 to $45 \mathrm{~kg}$ live weight on the performance and body composition of female and entire male pigs. Anim Prod 36, 193-199.

65. Campbell RG, Taverner MR \& Curic DM (1985a) The influence of feeding level on protein requirement of pigs between 20 and $45 \mathrm{~kg}$ live weight. Anim Prod 40, 489-496.

66. Campbell RG, Taverner MR \& Curic DM (1985b) Effect of sex and energy intake between 48 and $90 \mathrm{~kg}$ live weight on protein deposition in growing pigs. Anim Prod 40, 497-504.

67. Chiba LI, Lewis AJ \& Peo ER Jr (1991) Amino acid and energy interrelationships in pigs weighing 20 to 50 kilograms: I. Rate and efficiency of weight gain. J Anim Sci 69, 694-707.

68. Chiba LI, Lewis AJ \& Peo ER Jr (1991) Amino acid and energy interrelationships in pigs weighing 20 to 50 kilograms: II. Rate and efficiency of protein and fat deposition. J Anim Sci 69, 708-718.

69. Schroeder GF \& Titgemeyer EC (2008) Interaction between protein and energy supply on protein utilization in growing cattle: a review. Livest Sci 114, 1-10.

70. Susenbeth A (1995) Factors affecting lysine utilization in growing pigs: an analysis of literature data. Livest Prod Sci 43, 193-204.

71. Susenbeth A, Dickel T, Diekenhorst A, et al. (1999) The effect of energy intake, genotype, and body weight on protein retention in pigs when dietary lysine is the first-limiting factor. J Anim Sci 77, 2985-2989.

72. Slagter PJ \& Waldroup PW (1990) Calculation and evaluation of energy: amino acid ratios for the egg-production type hen. Poult Sci 69, 1810-1822.
73. Bell DD, Weaver WD \& North MO (2001) Commercial Chicken Meat and Egg Production, 5th ed. New York, NY: Springer.

74. Morris TR, Gous RM \& Fisher C (1999) An analyses of the hypothesis that amino acid requirements for chicks should be stated as a proportion of dietary protein. World's Poult Sci J 55, 7-22.

75. Lemme A (2007) How to adjust dietary amino acids to energy in broiler diets? Amino News 8, 13-24.

76. Schroeder GF, Titgemeyer EC, Awawdeh MS, et al. (2006) Effects of energy level on methionine utilization by growing steers. J Anim Sci 84, 1497-1504.

77. Schroeder GF, Titgemeyer EC \& Moore ES (2007) Effects of energy supplementation on leucine utilization by growing steers. J Anim Sci 85, 3348-3354.

78. Grau CR (1948) Effect of protein level on the lysine requirement of the chick. J Nutr 36, 99-108.

79. Morris TR, Al-Azzawi K, Gous RM, et al. (1987) Effects of protein concentration on responses to dietary lysine by chicks. Br Poult Sci 28, 185-195.

80. Sterling KG, Pesti GM \& Bakalli RI (2003) Performance of broiler chicks fed various levels of dietary lysine and crude protein. Poult Sci 82, 1939-1947.

81. Urdaneta-Rincon M, de Lange K, Peña-Ortega L, et al. (2005) Lysine requirements of young broiler chickens are affected by level of dietary crude protein. Can J Anim Sci 85, 195-204.

82. Cowey CB (1994) Amino acid requirements of fish: a critical appraisal of present values. Aquaculture 124, 1-11.

83. Mambrini M \& Guillaume J (2001) Protein nutrition. In Nutrition and Feeding of Fish and Crustaceans, pp. 81-110 [J Guillaum, SJ Kaushik, P Bergot and R Metailler, editors] London: Springer.

84. Rodehutscord M, Borchert F, Gregus Z, et al. (2000) Availability and utilisation of free lysine in rainbow trout (Oncorbynchus mykiss) 1. Effect of dietary crude protein level. Aquaculture 187, 163-176.

85. Abboudi T, Mambrini M, Ooghe W, et al. (2006) Protein and lysine requirements for maintenance and for tissue accretion in Atlantic salmon (Salmo salar) fry. Aquaculture 261 , 369-383.

86. Peres H \& Oliva-Teles A (1999) Effect of dietary lipid level on growth performance and feed utilization by European sea bass juveniles (Dicentrarchus labrax). Aquaculture 179, 325-334.

87. Geurden I, Gondouin E, Rimbach M, et al. (2006) The evaluation of energy intake adjustments and preferences in juvenile rainbow trout fed increasing amounts of lipid. Physiol Behav 88, 325-332.

88. Baker DH (1986) Problems and pitfalls in animal experiments designed to establish dietary requirements for essential nutrients. J Nutr 116, 2339-2349.

89. Rodehutscord M \& Pack M (1999) Estimates of essential amino acid requirements from dose-response studies with rainbow trout and broiler chicken: effect of mathematical model. Arch Anim Nutr 52, 223-244.

90. Shearer KD (2000) Experimental design, statistical analysis and modeling of dietary nutrient requirement studies for fish: a critical review. Aquacult Nutr 6, 91-102.

91. Kaushik SJ \& Seiliez I (2010) Protein and amino acid nutrition and metabolism in fish: current knowledge and future needs. Aquacult Res 41, 322-332.

92. Hua K, de Lange CFM, Birkett S, et al. (2010) Adaptation of a non-ruminant nutrient-based growth model to rainbow trout (Oncorbynchus mykiss Walbaum). J Agric Sci 148, 17-29. 